\title{
Peak Alpha Frequency in Relation to Cognitive Performance
}

\author{
Sushma Rathee ${ }^{1} \quad$ Divya Bhatia $^{2} \quad$ Vikas Punia ${ }^{3}$ \\ 1Department of Clinical Psychology, Post Graduate Institute of \\ Medical Education \& Research, Chandigarh, India \\ 2Department of Psychology, Sapienza University of Rome, \\ Rome, Italy \\ ${ }^{3}$ Department of Clinical Psychology, Shree Guru Gobind Singh \\ Tricentenary University, Gurugram, India
}

| Neurosci Rural Pract:2020;11:416-419

\author{
Rajbir Singh ${ }^{3}$
}

\begin{abstract}
Keywords

- cognitive performance

- power spectrum density

- peak alpha frequency

- reading comprehension

Objective Peak alpha frequency (PAF) is reported to be a nervous system property which is genetically endowed and reflected in individual's cognitive functioning. Cognitive performance denotes the mental processes for effective changes in response to situations in general and mental task in particular. None of the study has till now used reading comprehension as a measure of cognitive functioning, which is considered to be a measure of higher cognitive processes. The reading comprehension task used in the study implies certain cognitive processes such as reading ability, comprehension, memory performance involving information maintenance, and retrieval. Therefore, the study was conducted to test the hypothesis of differences in cognitive reading comprehension performance between high- and low-peak alpha subjects.

Materials and Methods A group of 300 healthy participants were selected on the basis of incidental-cum-probabilistic sampling from seven districts of Indian state of Haryana. In the present study, reading comprehension task (Hindi-English; bilingual format) was used to assess the cognitive performance and multichannel electroencephalography alpha frequencies were recorded to measure PAF through power spectrum density analysis of each subject.

Results The findings revealed that individuals with high-peak alpha frequency had significantly higher score $(p<0.05)$ on reading comprehension task as compared with individuals with low PAF.

Conclusion The present study concluded that the reading comprehension task is effected by peak alpha frequency of an individual. PAF can be considered to be a correlate of cognitive performance.
\end{abstract}

\begin{abstract}
Address for correspondence Rajbir Singh, PhD, Faculty of Behavioural Sciences, Shree Guru Gobind Singh Tricentenary University, Chandu- Budhera, Gurgaon, Badli Road, Gurugram, Haryana, 122505, India (e-mail: rajbirsinghmdu@gmail.com).
\end{abstract}

\section{Introduction}

The electroencephalography (EEG) is a noninvasive procedure to investigate the neural-electrophysiological parameters of the brain activity. EEG reveals stable individual differences in the functioning of the human brain. ${ }^{1}$ The alpha band frequencies have been found to be positively related with cognitive performance, such as attention and anticipation, while likely to decelerate with age. ${ }^{2}$ The continuous electrical activity in the brain produces different wave pattern in synchronization with different states such as waking, deep sleeping, dreaming state, etc. Alpha waves between 8 and $13 \mathrm{~Hz}$ obtained in waking state with their derived parameters such as individual alpha frequency (IAF)/peak alpha frequency (PAF) are reported to be nervous system property which is genetically endowed and reflected in an individual's 
cognitive functioning. ${ }^{3}$ Empirical studies on normal adults with standardized intelligence tests revealed a positive correlation with their average and peak EEG alpha frequencies. ${ }^{1}$ PAF or IAF is considered as an indicator of cognitive preparedness that may be a state or trait of an individual. Several comparative studies of healthy adults and clinical sample established the trait property of $\mathrm{PAF}^{4,5}$ whereas the role of PAF in the cognitive processing from lower attentional processes to higher level of semantic processing further attested to its role as state to state regulation within an individual. ${ }^{6}$ A positive correlation between PAF and cognitive performance has been reported confirmed. ${ }^{7}$ Reading performance as well as PAF continues to increase with maturation in healthy children. ${ }^{8}$ On the same lines, memory and speed of processing too correlated positively with PAF in healthy adults. ${ }^{5,9}$

Similarly, various studies revealed that different individuals with lower cognitive performances have reduced PAF and individuals with higher cognitive performance have increased PAF. ${ }^{10}$ However, none of the study selected reading comprehension as a measure of cognitive abilities which is considered to be a measure of higher cognitive abilities. The reading comprehension task involves attention, concentration, encoding, semantic processing, reading speed, and retrieval processes, etc. Therefore, the present study is conducted to test the hypothesis to see the difference in cognitive reading comprehension performance between high- and low-peak alpha subjects.

\section{Materials and Methods}

\section{Sample}

A total number of 300 healthy young adults (males $=151$, females $=149$ ) from the age group of 18 to 30 years ( mean $=22.38$ years, standard deviation $[S D]=2.8$ ) and education range from 12 to 17 years of education with mean years of education ( mean $=14.53, \mathrm{SD}=1.54$ ), who voluntarily consented participated in the study were largely selected from college and universities located in seven districts of Haryana, that is, Rohtak, Bhiwani, Sonipat, Mahendragarh, Kurukshetra, Jind, and Gurugram. Most of the samples included in the present study belong to rural areas (66.67\%). Though, they were students but at that time, they were staying in their villages beyond the college hours. The method adopted for participant's selection was incidental-cumprobabilistic sampling. Every participant signed the written consent form and was briefed about the study. The demographic details of the same are presented in - Table $\mathbf{1}$.

\section{Measure Used for Cognitive Performance}

\section{Reading comprehension}

In the present study, a comprehension task was prepared and its computerized version in a bilingual format (Hindi and English) followed by seven questions was given to subjects. It measures the long term and working memory of the participant. The difficulty of paragraph was ascertained through a pilot study conducted on 10 participants. Four multiple choice response formats was used for each question. The subjects were allowed to read and comprehend the paragraph thoroughly. Further, the subjects were categorically informed that while answering the questions the paragraph will not be visible on the screen. Participants were free to choose the language of their interest for reading and subsequently answering the questions. The correct responses were awarded with score 1 while incorrect response with 0 to each question. The reading time of the comprehension and answering a multiple type questions was fixed on the basis of pilot study on 10 bilingual subjects in college. None of the subjects in pilot study took time beyond this during testing. It was timed for 5 minutes for reading paragraph after which the question popped up in the screen for 30 seconds for multiple choice

Table 1 Demographic details of participants

\begin{tabular}{|c|c|c|c|}
\hline Variables & Description & Frequency/mean & Percent/standard deviation \\
\hline Education & & 14.53 & 1.54 \\
\hline \multirow[t]{2}{*}{ Gender } & Male & 151 & 50.33 \\
\hline & Female & 149 & 49.67 \\
\hline \multirow[t]{2}{*}{ Residence } & Rural & 200 & 66.67 \\
\hline & Urban & 100 & 33.33 \\
\hline \multirow[t]{3}{*}{ Marital status } & Married & 98 & 32.67 \\
\hline & Unmarried & 201 & 67.00 \\
\hline & Separated & 1 & 0.33 \\
\hline \multirow[t]{2}{*}{ Family type } & Joint & 142 & 47.33 \\
\hline & Nuclear & 158 & 52.67 \\
\hline \multirow[t]{5}{*}{ Occupation } & Farmer & 83 & 27.67 \\
\hline & Student & 213 & 71.00 \\
\hline & Government job & 2 & 0.67 \\
\hline & Private Job & 1 & 0.33 \\
\hline & Self-business & 1 & 0.33 \\
\hline \multirow[t]{3}{*}{ Religion } & Hindu & 294 & 98 \\
\hline & Sikh & 4 & 1.33 \\
\hline & Muslim & 2 & 0.67 \\
\hline
\end{tabular}


questions. If a subject does not answer within 30 seconds, next question automatically came out.

\section{Physiological Measures}

Peak alpha frequency and individual alpha frequency.

\section{Electroencephalography Data Acquisition and Analysis}

1. Equipment: EEG was recorded with a 19-channel, portable, digital, and easy to use EEG machine provided by Medicaid Systems, Chandigarh, India with 15 inches laptop (Dell Vostro 3568; Intel core i5 processor, Refresh rate $60 \mathrm{~Hz}$ ). Silver Chloride plated metal disc electrodes were used to measure the brain activity from scalp.

2. Procedure: The data were collected always by the two well-trained qualified junior research associates. Participants were instructed to thoroughly clean their hair and dry them before their participation in the study. EEG data were collected in an isolated room with peaceful environment, florescent lighting, and no other person was present except for the participant and the investigators. An EEG electrode cap with less than 5k Ohms impedance was fitted with the participants and resting state EEG was recorded for 8 to 10 minutes. They were seated comfortably on an arm-chair during the recording and were instructed to remain still, relaxed and eyes closed. Electrodes were placed using 10 to 20 international electrode placement system with reference electrodes at ear lobes, and data were recorded in eyes closed condition. Six electrodes, relevant to alpha waves $(\mathrm{Fz}$, $\mathrm{Cz}, \mathrm{P}_{3}, \mathrm{Pz}, \mathrm{P}_{4}, \mathrm{O}_{1}$ ) were selected for further analysis using power spectrum density (PSD) method ${ }^{10-12}$ using MATLAB software.

\section{Data Analysis}

Eye blink artifacts were removed after visual inspection of raw EEG data which then was analyzed using the EEGLAB toolbox on MATLAB. First 2 minutes data for each participant were divided into three epochs of 40 seconds. PSD function in the EEGLAB toolbox was applied to each set of data which showed different peaks for each of the frequency range for each electrode point. The highest peak in the alpha frequency range was visually inspected and noted down for each dataset, which was the PAF for the corresponding dataset. Three PAFs for each electrode point were calculated using PSD, and the average of it makes the PAF for the corresponding electrode. The average of peak frequency of all six electrodes makes the individual frequency for each participant.

Statistical analysis on the PAF and IAF was performed by SPSS (- Table 2).

\section{Creation of Groups}

Out of total sample of 300 , the groups were selected on the basis of a criterion of mean +1 standard deviation (SD) and above for high PAF group (More than 11.91) and mean-1 SD and below for low PAF group (less than 7.95). It was found that the two groups comprised 71 and 53 subjects in high and low PAF groups, respectively. Thus, extreme polar group design was used, and the hypothesis was tested by applying $t$-test for independent sample.

\section{Results}

- Table 3 shows the difference on cognitive performance between individuals with high PAF and individuals with low PAF. It revealed that there was a significant difference

Table 2 Individual peak alpha frequency for six electrode points, overall individual alpha frequency of sample, and overall peak alpha frequency of sample

\begin{tabular}{|l|l|l|l|}
\hline & $n$ & Mean & SD \\
\hline $\mathrm{Fz}$ & 250 & 8.56 & 1.59 \\
\hline $\mathrm{Cz}$ & 250 & 8.59 & 1.64 \\
\hline $\mathrm{P}_{3}$ & 250 & 8.82 & 1.82 \\
\hline $\mathrm{Pz}$ & 250 & 8.86 & 1.85 \\
\hline $\mathrm{P}_{4}$ & 250 & 8.76 & 1.74 \\
\hline $\mathrm{O}_{1}$ & 300 & 8.74 & 1.76 \\
\hline IAF & 300 & 8.65 & 1.41 \\
\hline PAF & 300 & 9.93 & 1.98 \\
\hline
\end{tabular}

Abbreviations: IAF, individual alpha frequency; PAF, peak alpha frequency; SD, standard deviation.

Table 3 Showing the difference on cognitive performance between individual with high-peak alpha frequency and individual with low-peak alpha frequency

\begin{tabular}{|l|l|l|l|l|l|}
\hline Variable & $\begin{array}{l}\text { Individual with high PAF } \\
\text { mean } \pm \text { SD } \\
(\boldsymbol{n}=71)\end{array}$ & $\begin{array}{l}\text { Individual with low PAF } \\
\text { mean } \pm \text { SD } \\
(\boldsymbol{n}=53)\end{array}$ & $\boldsymbol{d}$-Value \\
\hline Reading comprehension task & $5.22 \pm 1.22$ & $4.75 \pm 1.19$ & 2.14 & 122 & 0.034 \\
\hline
\end{tabular}

Abbreviations: IAF, individual alpha frequency; PAF, peak alpha frequency; SD, standard deviation. 
$(p<0.05)$ in reading comprehension scores between high PAF and low PAF groups. It showed that individual with high PAF had significantly higher score (5.22) on reading comprehension task as compared with individual with low $\operatorname{PAF}(4.75)$.

\section{Discussion}

The present study was aimed to see the difference in cognitive reading comprehension performance between high- and low-peak alpha subjects. Results revealed that individual with high PAF have significantly higher score on reading comprehension task as compared with individual with PAF. However, there is no study which measured reading comprehension task in relation to PAF. Though, there are studies which showed the association of PAF with better cognitive functions such as memory, attention, and reading abilities. ${ }^{10,13}$

The present study suggested that the reading comprehension task, a composite of several cognitive processes from basic to higher level is found to be related to PAF. Hence, it is concluded that high PAF is a positive correlate of cognitive performance.

On the basis of the present study, it was noticed that PAF seems to be a nervous system property distributed widely and perhaps normally. However, this fact may be further ascertained by applying the measure of PAF on a larger sample of all age groups. It appears to have a status of nervous system trait which happens to be a correlate of cognitive performance. However, some more complex problem-solving tasks, decision-making, etc. can be studied in relation to PAF/IAF.

The objective of the study was examining a relationship between PAF and cognitive functioning. It was found that individual with high PAF have better cognitive performance as compared with individual with low PAF. On the basis of present study, it can be concluded that PAF seems to be associated with better cognitive performance among healthy individuals. One of the possible implications of this study is that those who have reduced PAF or lower performance on reading task should be screened regularly to avoid further cognitive deterioration.

\section{Funding}

This work was supported by a grant awarded to Rajbir Singh from Department of Science and Technology, Government of India, [reference no. SR/CSRI/40/2014] under Cognitive Science Research Initiative (CSRI) program. This research was conducted at Maharishi Dayanand University, Rohtak.

\section{Conflict of Interest}

R.S. reports grants from the Department of Science and Technology during the conduct of the study. V.P. reports grants from the Department of Science and Technology outside the submitted work.

\section{References}

1 Anokhin A, Vogel F. EEG alpha rhythm frequency and intelligence in normal adults. Intelligence 1996;23(1):1-14

2 Richard Clark C, Veltmeyer MD, Hamilton RJ, et al. Spontaneous alpha peak frequency predicts working memory performance across the age span. Int J Psychophysiol 2004;53(1):1-9

3 Grandy TH, Werkle-Bergner M, Chicherio C, Schmiedek F, Lövdén M, Lindenberger U. Peak individual alpha frequency qualifies as a stable neurophysiological trait marker in healthy younger and older adults. Psychophysiology 2013;50(6):570-582

4 Passero S, Rocchi R, Vatti G, Burgalassi L, Battistini N. Quantitative EEG mapping, regional cerebral blood flow, and neuropsychological function in Alzheimer's disease. Dementia 1995;6(3):148-156

5 Klimesch W, Schimke H, Ladurner G, Pfurtscheller G. Alpha frequency and memory performance. J Psychophysiol 1990;4:381-390

6 Doppelmayr M, Klimesch W, Stadler W, Pöllhuber D, Heine C. EEG alpha power and intelligence. Intelligence 2002;30(3): 289-302

7 Angelakis E, Stathopoulou S, Frymiare JL, Green DL, Lubar JF, Kounios J. EEG neurofeedback: a brief overview and an example of peak alpha frequency training for cognitive enhancement in the elderly. Clin Neuropsychol 2007;21(1):110-129

8 Suldo SM, Olson LA, Evans JR. Quantitative EEG evidence of increased alpha peak frequency in children with precocious reading ability. J Neurother 2001;5(3):39-50

9 Hemler RJ, Hoogeveen JH, Kraaier V, et al. A pharmacological model of cerebral ischemia. The effects of indomethacin on cerebral blood flow velocity, quantitative EEG and cognitive functions. Methods Find Exp Clin Pharmacol 1990;12(9): 641-643

10 Angelakis E, Lubar JF. Quantitative electroencephalographic amplitude measures in young adults during reading tasks and rest. J Neurother 2002;6(2):5-19

11 Valipour S, Shaligram AD, Kulkarni GR. Detection of an alpha rhythm of EEG signal based on EEGLAB. Int J Eng Res Appl 2014;4(1):154-159

12 Rathee S, Bhatia D, Singh R. Is it necessary to measure all brain regions for the assessment of PAF? Int J Eng Res Appl 2017;7(12):72-76

13 Klimesch W, Schimke H, Pfurtscheller G. Alpha frequency, cognitive load and memory performance. Brain Topogr 1993;5(3):241-251 